\title{
Sizing and Mission Profile Analysis of the Hybrid-Electric Propulsion System for Retrofitting a Fixed Wing VTOL Aircraft
}

\author{
Jianan Zong $\mathbb{D}^{D}$, Bingjie Zhu $\mathbb{D}$, Zhongxi Hou, Xixiang Yang, and Jiaqi Zhai \\ College of Aerospace Science and Engineering, National University of Defense Technology, Changsha, Hunan 410073, China \\ Correspondence should be addressed to Bingjie Zhu; jackerzhu@163.com
}

Received 28 June 2021; Revised 15 December 2021; Accepted 4 January 2022; Published 7 February 2022

Academic Editor: Jun-Wei Li

Copyright (C) 2022 Jianan Zong et al. This is an open access article distributed under the Creative Commons Attribution License, which permits unrestricted use, distribution, and reproduction in any medium, provided the original work is properly cited.

\begin{abstract}
Hybrid-electric technology can be expected to improve the performance of fixed wing vertical takeoff and landing (VTOL) aircraft. In this paper, we demonstrated a method of retrofitting a single-energy propulsion system prototype with a hybridelectric propulsion system. Since the hybrid-electric system has several working modes, the optimal design results have strong coupling with mission performance. Therefore, we propose an analysis method of the mission profile to determine the design point. Finally, the payload-range sensitivity is studied. The results show that the hybrid-electric propulsion system can greatly increase the mission profile of aircraft. The analysis method of the mission profile also provides perspective for the hybridelectric propulsion system design.
\end{abstract}

\section{Introduction}

In the Urban Air Mobility (UAM) market, transport companies, aircraft manufacturers, and technology companies are working with government organizations to operate on demand and scheduled operations using quiet, efficient manned and unmanned vehicles. Functions include emergency medical evacuation, rescue operations, humanitarian missions, news gathering, ground traffic flow assessment, weather monitoring, parcel delivery, and passenger transport to alleviate urban land area problems and ground traffic congestion. The VTOL aircraft is the most likely candidate for safe and efficient urban transport, with electric or hybrid-electric propulsion systems and advanced technical concept navigation [1-3]. The fixed wing VTOL aircraft integrates the configuration of fixed wing and rotary wing and has the characteristics of high speed, low power consumption, and agile maneuverability [4]. On the other hand, the energy saving, environmental protection, stability, and safety of electric propulsion technology, especially the free design architecture of the propulsion system, have good coupling with the configuration of fixed wing VTOL aircraft [5]. With the rapid development of battery technology, electric propulsion technology is expected to be more widely used in the aviation industry [6].

Limited by the current battery energy density, and the progress of battery energy density is very slow, with an average of $8 \%$ per year [7]. Therefore, hybrid-electric propulsion has more potential at present [8]. The hybrid-electric system is usually classified as three categories by configuration: series, parallel, and complex. Series hybrid-electric system combines an internal combustion engine (ICE) and motor to form a propulsion mode with complementary power, because the efficiency of ICE is low and greatly affected by the working point. However, the efficiency of the motor is high. Through reasonable optimization, the overall efficiency of the propulsion system can be improved. In addition, electric propulsion components bring more flexibility in the design of aircraft and the propulsion system, because once the mechanical connection is converted to electrical connection, it is easy to drive electronic speed control (EMS) without affecting ICE performance [9]. These advantages make the series hybrid system to be first applied to VTOL light aircraft and small or medium UAVs to improve emissions, endurance, payload capacity, and noise [10-14], because there is a significant mismatch of power demand between 
the vertical process and stable cruise of this kind of aircraft, and the multipropeller layout is often used.

Design procedures and best practices for hybrid-electric aircraft are yet to be developed. The main reason is that the hybrid-electric system has more complex configuration. Iteration method can estimate the wing area and the initial size of aircraft with traditional propulsion configuration, and many studies have improved the iteration method to make it applicable for hybrid-electric aircraft [10, 15-19]. This iteration method is to obtain the optimal design (minimum weight or fuel consumption, etc.) satisfying the performance through continuous iterative calculation. The advantage of this method is that the parameters of the propulsion system, aircraft weight, and wing area change at the same time in each iteration process. Therefore, the propulsion system and aircraft design parameters are interrelated. However, since this method is based on a certain mission profile, the calculated fuel mass does not correspond to the designed maximum fuel loading of the tank. Minor mass changes will affect the final results of all parameters in the iteration process, so this method can only be used as a preliminary size estimation. The design method proposed in this paper is based on retrofitting a fixed wing VTOL aircraft. It is essentially a design method of the hybrid-electric propulsion system with known parameters of the aircraft except the propulsion system. By changing the parameters of the aircraft (MTOM, AR, etc.) the design of different hybrid-electric fixed wing VTOL aircrafts can still be involved.

\section{Hybrid-Electric Propulsion System of Fixed Wing VTOL Aircraft}

Cakin et al. [17] considered all configurations and concluded that series hybrid is the preferred hybrid configuration for VTOL aircraft. In the series hybrid concept, the propeller is driven by an electric motor. The mechanical power of the ICE flows through the generator and is converted into electricity at the generator side. The battery can also be charged through the generator set. The ICE is separated from the thrust. Therefore, the ICE can operate at nominal operating conditions. This basic configuration enables easy control of speed of ICE. The configuration of fixed wing VTOL aircraft and series hybrid system is shown in Figure 1.

2.1. Definition of Hybridization. The major index to evaluate the electrical level of a hybrid-electric system is the degree of hybridization, but there are many definitions of hybridization, and the representative one is the hybridization of power $[13,15]$ such as the maximum power ratio of motor to ICE. The other is defined from the energy, which is the ratio of the battery energy to the total energy [15]. There is also a hybridization defined in terms of mass fraction [20], which is the ratio of battery mass to the total mass of the propulsion system. Although these definitions of hybridization have different expressions, they are essentially the same concept. Among them, the hybridization defined by mass fraction was considered the best choice because other definitions contain unnecessary parameters. In this paper, this definition of hybridization is introduced and improved to make it more applicable for the series hybrid system.

Since the series hybrid system contains a generator, the ICE is essentially a generator set, that is, the combination of ICE and generator. Fuel mass is determined by fuel tank volume and has no special relationship with other parameters of the propulsion system, so it is not necessary to be included in the definition of hybridization. Therefore, the hybridization $\gamma$ is defined as

$$
\gamma=\frac{m_{b}}{m_{b}+m_{e}+m_{g}}
$$

where $m_{b}$ is the battery mass, $m_{e}$ is the ICE mass, and $m_{g}$ is the generator mass.

2.2. Mass and Working Characteristics of the Propulsion System. The MTOM of aircraft can be expressed as the sum of empty weight, payload, and energy mass [5]:

$$
\mathrm{MTOM}=M_{\text {empty }}+M_{\text {payload }}+M_{\text {energy }} .
$$

After expanding the MTOM, the equation can be written as

$$
\begin{aligned}
\text { MTOM }= & M_{\text {struct }}+M_{\text {subsyst }}+M_{\text {avion }}+M_{\text {propeller }}+M_{\text {payload }} \\
& +\left(M_{\mathrm{ICE}}+M_{\mathrm{GE}}+M_{\text {batt }}\right)+M_{\text {fuel }},
\end{aligned}
$$

where the payload, as the performance, is given by the design requirements, and the mass of the rest is known. ( $\left.M_{\mathrm{ICE}}+M_{\mathrm{GE}}+M_{\mathrm{batt}}\right)+M_{\text {fuel }}$ is the same as the battery mass of the prototype, also a known value. $M_{\text {fuel }}$ can be preset, and $M_{\mathrm{ICE}}, M_{\mathrm{GE}}$, and $M_{\text {batt }}$ can be completely characterized by $\gamma$. According to the research of Cakin et al. [17], the technical evaluation of the hybrid power system is shown in Table 1.

The working characteristics of ICE are greatly affected by speed and brake mean effective pressure (BEMP), so it cannot be simply equivalent by efficiency. It can be described by map, but map depends on test data. In this paper, the characteristics of the engine are simulated with the help of the "general engine" simulation block in Simulink. The block provides fuel consumption characteristics related to speed and BEMP, as shown in Figure 2.

Economou et al. [13] and Wang and Mesbahi [21] indicated that the ICE working in the best working area is conducive to energy saving, which will be the main basis for the relationship between ICE output power and fuel consumption.

2.3. Power Demand. The flight conditions of fixed wing VTOL aircraft include climb and cruise. The power demand in fixed wing mode can be expressed as [22]

$$
P_{\text {req }}=\frac{\beta W}{\eta_{p}}\left\{\frac{V}{\beta}\left(K \frac{\beta^{2}}{q}\left(\frac{W}{S}\right)+\frac{q C_{D 0}}{(W / S)}\right)+\frac{1}{g}\left(\frac{d}{d t}\left(h+\frac{V^{2}}{2 g}\right)\right)\right\},
$$




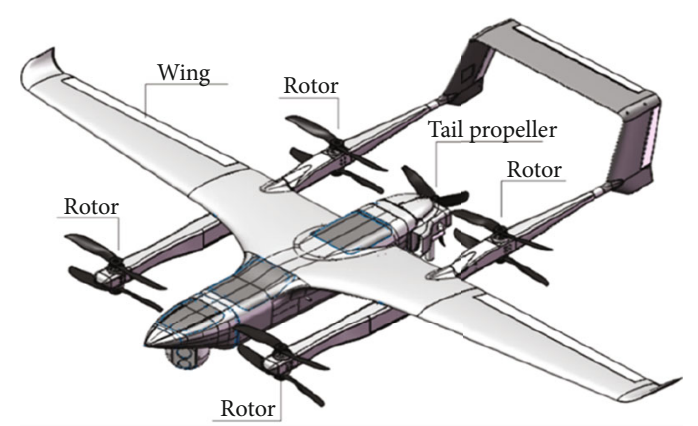

(a)

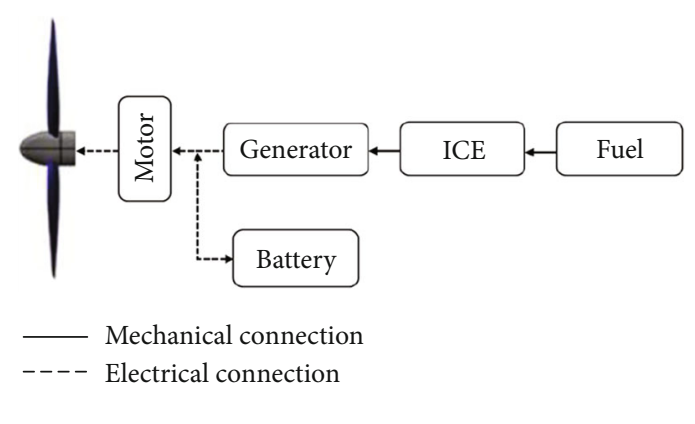

(b)

Figure 1: Configuration of fixed wing VTOL aircraft and series system. (a) Fixed wing VTOL aircraft. (b) Series system.

TABLE 1: Technology assessment of hybrid-electric systems [17].

\begin{tabular}{lcc}
\hline Parameters & Min & Max \\
\hline Electric motor efficiency & 0.86 & 0.98 \\
Generator efficiency & 0.86 & 0.98 \\
Battery efficiency & 0.8 & 0.99 \\
Battery power density $(\mathrm{kW} / \mathrm{kg})$ & 0.35 & 0.8 \\
Battery energy density $(\mathrm{Wh} / \mathrm{kg})$ & 151 & 260 \\
ICE power density $(\mathrm{kW} / \mathrm{kg})$ & 0.25 & 3 \\
Electric motor power density $(\mathrm{kW} / \mathrm{kg})$ & 3 & 5 \\
\hline
\end{tabular}

where $W$ is the total takeoff weight, $\beta$ is the fuel consumption coefficient which is the ratio of current fuel weight to the initial fuel weight, $q$ is the dynamic head, and $C_{D 0}$ is the zero drag coefficient; $K=1 /(\pi e \times A R)$ is the drag coefficient due to lift, where aspect ratio (AR) is the wing aspect ratio, $e$ is the Oswald factor, $h$ is the flight height, $d h / d t$ is the climb rate, $V$ is the flight speed, and $\eta_{p}$ is the propeller efficiency.

The typical working conditions of a rotary wing include hovering, conversion, vertical takeoff and landing, etc. The formula for calculating the power of propeller/rotor can be derived from the momentum theory [23]:

$$
P_{\text {req }}=\frac{\beta W}{2 F M} \frac{T}{W}\left\{\left(\left(\frac{d h}{d t}\right)^{2}+4 v_{i}^{2}\right)^{0.5}-\frac{d h}{d t}\right\} .
$$

The flight condition of the mode conversion process is complex, but the duration is very short, so the energy consumption is little. In order to simplify the analysis of the mission profile, this condition will not be considered, which makes the analysis of the mission profile more concise and intuitive.

\section{Design and Analysis Methods}

Compared with the traditional power system, the hybridelectric system has more than one energy storage unit, so it has more working modes. In the course of flight, the fuel efficiency can be improved by selecting the optimal working mode. Therefore, it is necessary to analyze the working mode before the analysis of the hybrid-electric propulsion system.

3.1. Working Mode Analysis. Finger et al. [24] pointed out that hybrid-electric propulsion should be considered if the size of the propulsion system depends on short-term power limitation (such as takeoff and climb). However, if the size of the system is based on continuous power demand (e.g., cruise), hybrid-electric propulsion has little benefit. In the study of fixed wing aircraft by Lammen and Vankan [25], the power allocation plan of each flight phase can be simply described as that the takeoff and climb phases are driven by hybrid power, and the other phases are only driven by the ICE. In the study of Gladin et al. [8], unlike the former, the battery is charged in the "cruise charging" task. Based on these studies, the basic working mode of fixed wing VTOL hybrid-electric aircraft is determined. The power distribution diagram of the entire flight process is shown in Figure 3.

In each flight phase, the power demand of the vertical process or conversion phase is high, but the duration time is short, so hybrid driving is suitable. The power demand in cruise phase is low but the duration time is long. Therefore, it is driven by ICE alone, and the battery needs to be charged during flight to improve ICE efficiency and ensure that the aircraft can complete vertical takeoff again.

3.2. Design Process. Theoretically, when the power of the power system can meet the power demands of the aircraft, the aircraft can take off, and the maximum power requirements of different flight phases can be calculated through Equations (4) and (5). Given the payload and fuel mass, the mass of ICE, generator, and battery can be expressed by only one value of $\gamma$, and the design of the hybridelectric propulsion system can be completed. Since the maximum output power of ICE, generator, and battery is related to the mass, the output power range of the power system can be obtained through the parameters given in Table 1. To meet the power demands, the value range of $\gamma$ is reduced to an acceptable region. The design flow is shown in Figure 4.

According to the working mode of the hybrid-electric system, it is difficult to give a design result only on the basis of the battery proportion, which needs to be combined with the mission profile of the aircraft. 


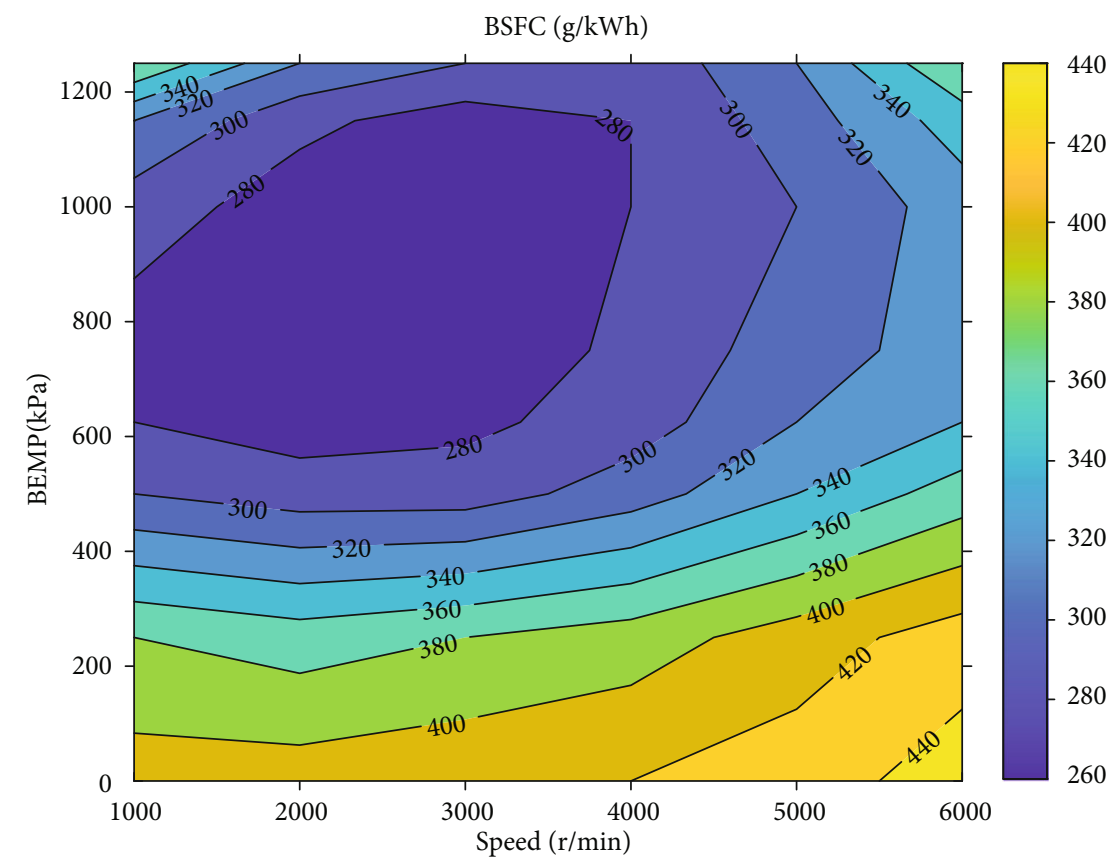

Figure 2: Map of ICE.

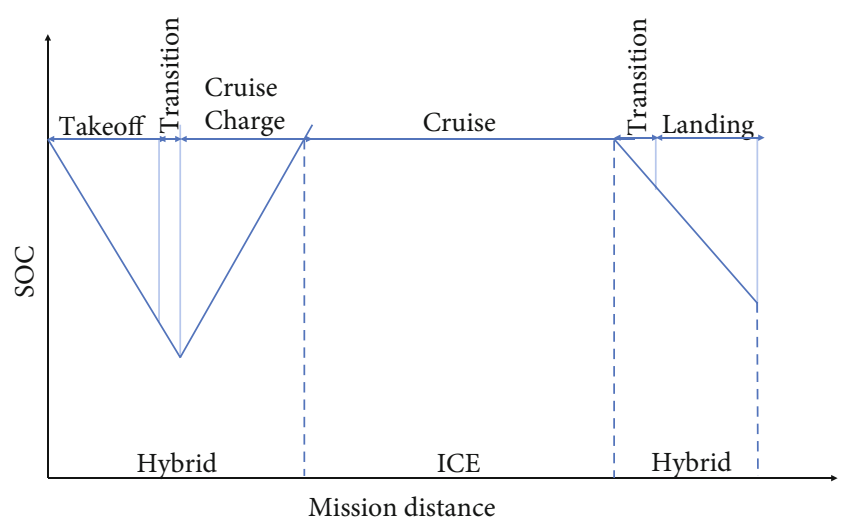

Figure 3: Power distribution diagram of the entire flight process.

3.3. Mission Profile Analysis Method. The flight profile boundary is closely related to the energy mass. A flight profile of a fixed wing VTOL aircraft can be abstracted as a quadrilateral. For a hybrid-electric fixed wing VTOL aircraft, there will be different flight profiles according to the working mode of the series hybrid system of different mission requirements, as shown in Figure 5.

Assuming that the aircraft takes off vertically to a certain altitude, and all the remaining energy is used to satisfy subsequent flights, the flight profile of the aircraft is the boundary of all mission profiles at this altitude. In Figure 5, taking the blue area as an example, when the aircraft takes off to the corresponding altitude, the aircraft cruises the farthest to the black point 1 . Therefore, the blue area is the boundary of the flight profile at the corresponding altitude. The green and yellow areas are the boundary of the mission profile at this altitude, respectively. It can be seen from Figure 5 that the curve (dashed line) obtained by connecting the farthest cruise point (black point) is the boundary of all mission profiles. That is, the energy satisfies the flight within the boundary line. Different mission profile areas of different $\gamma$ can be obtained by the above method, which will be used for hybrid-electric system design and evaluation.

\section{Case Studies}

This section gives the basic parameters of the prototype. The prototype refers to EMTORCH's GT-VTOL-E6 fixed wing VTOL aircraft [26]. The hybrid-electric system is designed through the process, and the basic parameters of the aircraft are shown in Table 2.

The available power of the power system needs to meet two constraints: (1) greater than the maximum power demand; (2) the available power of ICE and generator is greater than the power demand of stable cruise to charge the battery. This paper assumes that the available power of ICE is 1.2 times of the power demand of stable cruise. That is

$$
\begin{gathered}
P_{\text {tot }}>P_{\text {req }} \\
P_{\text {ICE }}>1.2 \times P_{\text {req,cruise }} \text {. }
\end{gathered}
$$

The point performances of the aircraft are given in Table 3.

Based on the given prototype parameters and point performances, the four battery and six battery modes in Table 2 are taken as two cases for analysis.

4.1. Case 1. Take $\gamma \in[0.1,0.9]$; by traversing $\gamma$, the acceptable region obtained is shown in Figure 6. Only $\gamma \in[0.10,0.72]$ 


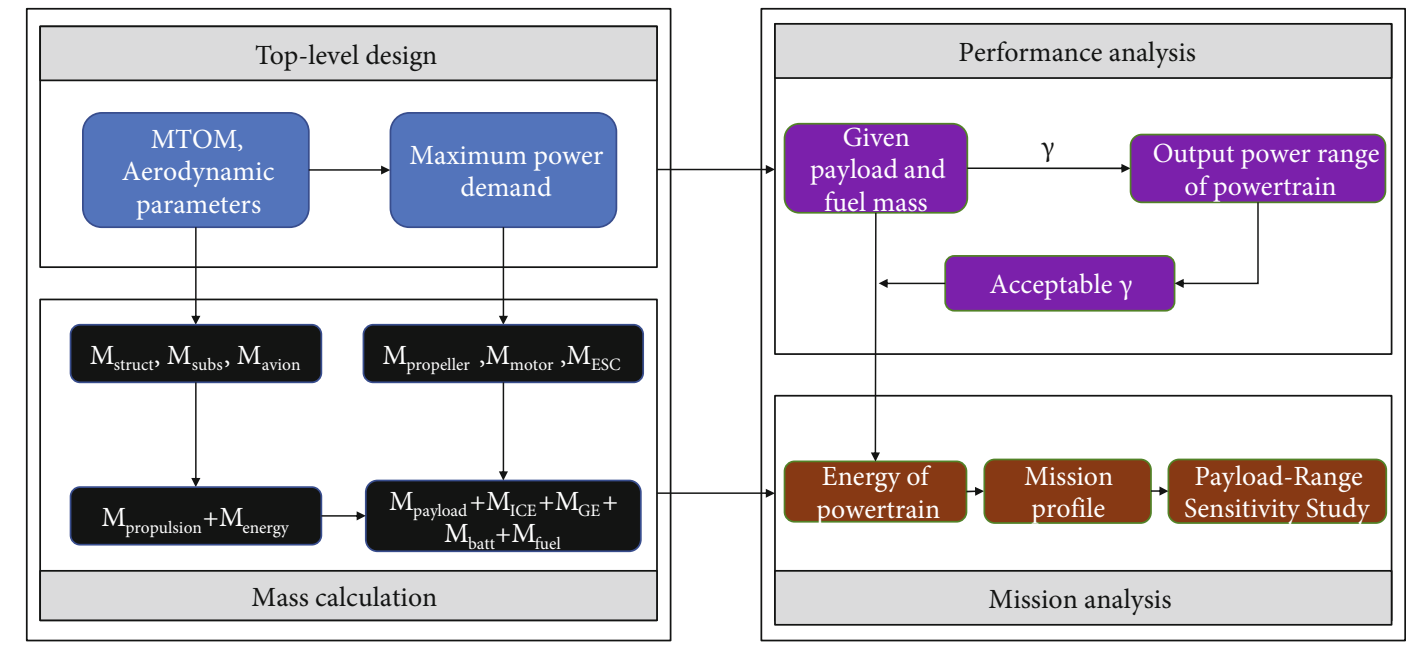

Figure 4: Design flow.

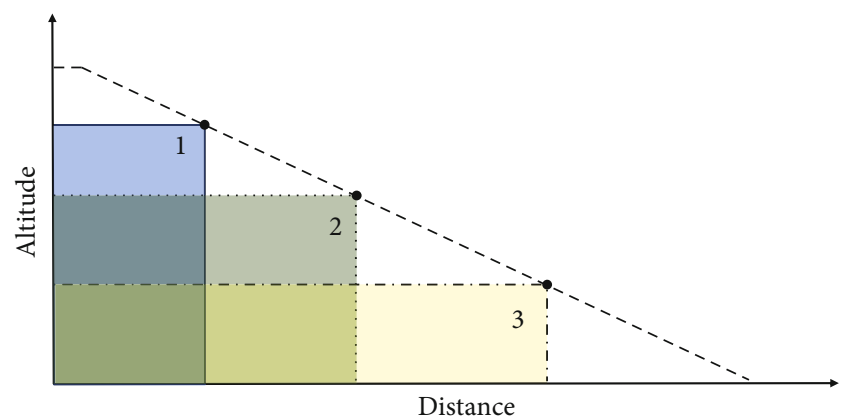

FIgURE 5: Flight profile diagram.

TABLE 2: Basic parameters of prototype.

\begin{tabular}{lc}
\hline Parameters & Value \\
\hline MTOM (kg) & 36 \\
Empty weight $(\mathrm{kg})$ & 16 (no battery) \\
& 26 (four batteries) \\
Tank volume (L) batteries) \\
Payload (kg) & 8 \\
Ceiling (m) & 5 \\
Zero drag coefficient & 2000 \\
Lift coefficient & 0.04 \\
Rotary wing drag coefficient & 0.5 \\
Wing area (m ${ }^{2}$ ) & 2 \\
Oswald factor & 0.8 \\
AR & 0.6850 \\
Power system efficiency (\%) & 15 \\
\hline
\end{tabular}

TABLE 3: Basic performances.

\begin{tabular}{lc}
\hline Parameters & Value \\
\hline Rate of climb $(\mathrm{m} / \mathrm{s})$ & 3 \\
Cruise speed $(\mathrm{m} / \mathrm{s})$ & $24(31 \mathrm{~kg}), 26(36 \mathrm{~kg})$ \\
\hline
\end{tabular}

can satisfy Equations (6) and (7), which is the acceptable region.

Combined with Section 3.3, through traversing $\gamma$ in the acceptable region, the mission profile area of the aircraft of different $\gamma$ is obtained, and the mission profile area of the prototype is also given, as shown in Figure 7.

It can be seen from Figure 7 that the mission profile of the pure-electric propulsion system has the smallest area and poor endurance performance, and the only advantage is the maximum flight altitude. For hybrid-electric systems, the higher the value of $\gamma$, the larger the maximum cruise distance is at the same altitude, but the lower the maximum takeoff altitude. When $\gamma$ is low, it has a significant impact on the maximum takeoff altitude, reducing $\gamma$ can significantly improve the maximum flight altitude of the aircraft; when $\gamma$ is high, it has a significant impact on the maximum cruise distance, reducing $\gamma$ can significantly improve the maximum flight altitude of the aircraft.

4.2. Case 2. The weight of the propulsion system in case 2 is $5 \mathrm{~kg}$ heavier than that in case 1 , so the power margin is larger. After traversing $\gamma$, it is found that all $\gamma \in[0.1,0.9]$ can meet the power demand, as shown in Figure 8.

Repeating the process of case 1 , the mission profile area of the prototype is also given, as shown in Figure 9.

In this paper, the ceiling is $2000 \mathrm{~m}$, so it is obvious that when $\gamma<0.6$, it is not the choice, because the mission area can be completely covered by $\gamma=0.6$. However, the maximum cruising distance is much smaller than that in case 1 , because the fuel tank has not changed and the weight of the aircraft has increased. Compared with case 1, it is found that the weight of the hybrid-electric system in case 2 is higher than that in case 1, so the output power of propulsion system has more redundancy. In case 2 , the maximum flight altitude is significantly higher than that in case 1 , but the maximum cruise distance is not. This is because the fuel quality of the two cases is the same, but the weight of the aircraft in case 2 is larger and requires more energy. Considering the power redundancy, the weight of the propulsion system can be reduced to increase the payload. 


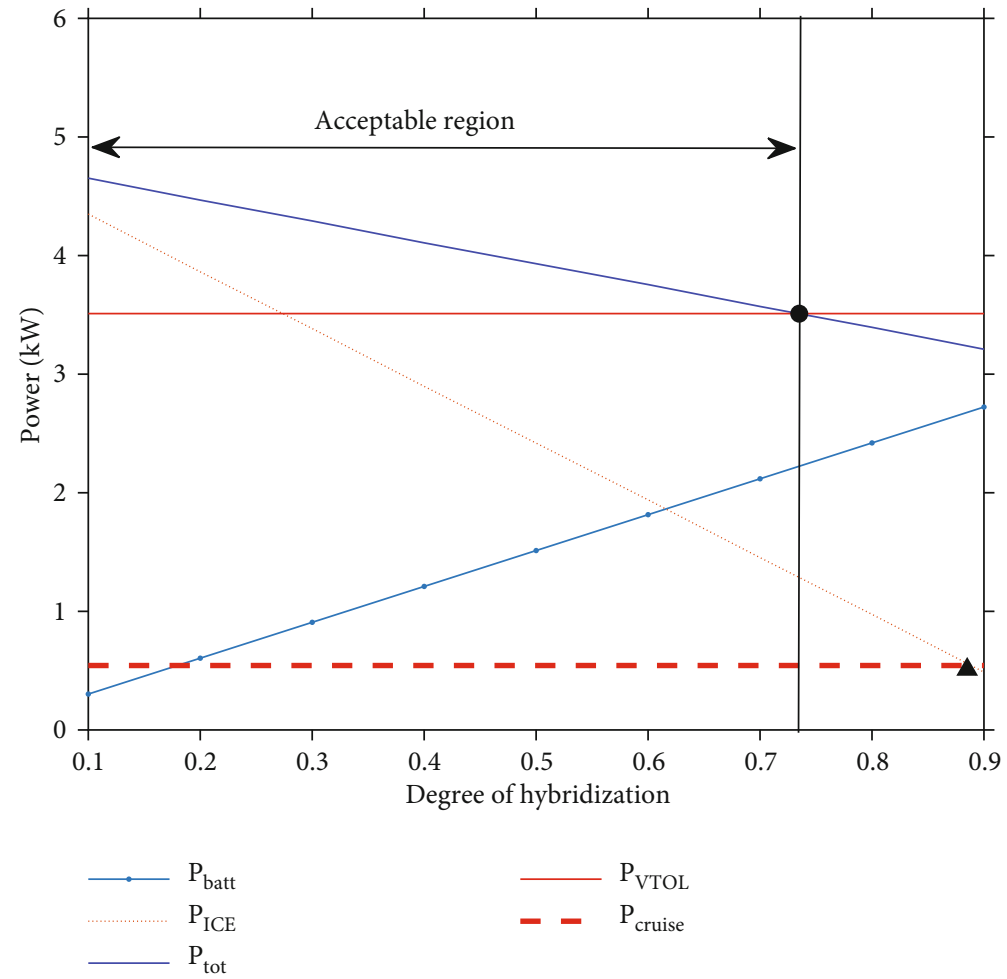

Figure 6: Acceptable region of $\gamma$.

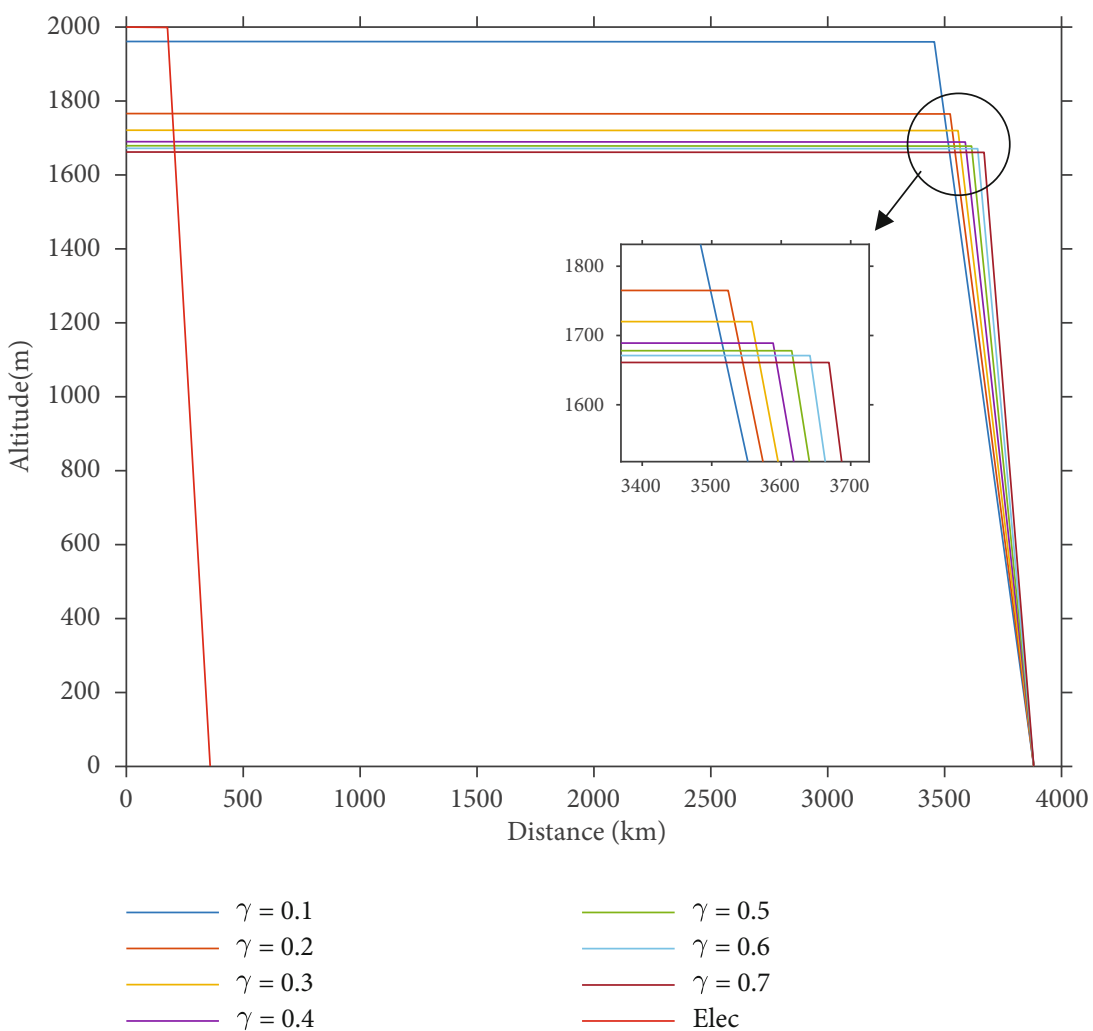

FIgURE 7: Different areas of the mission profile. 


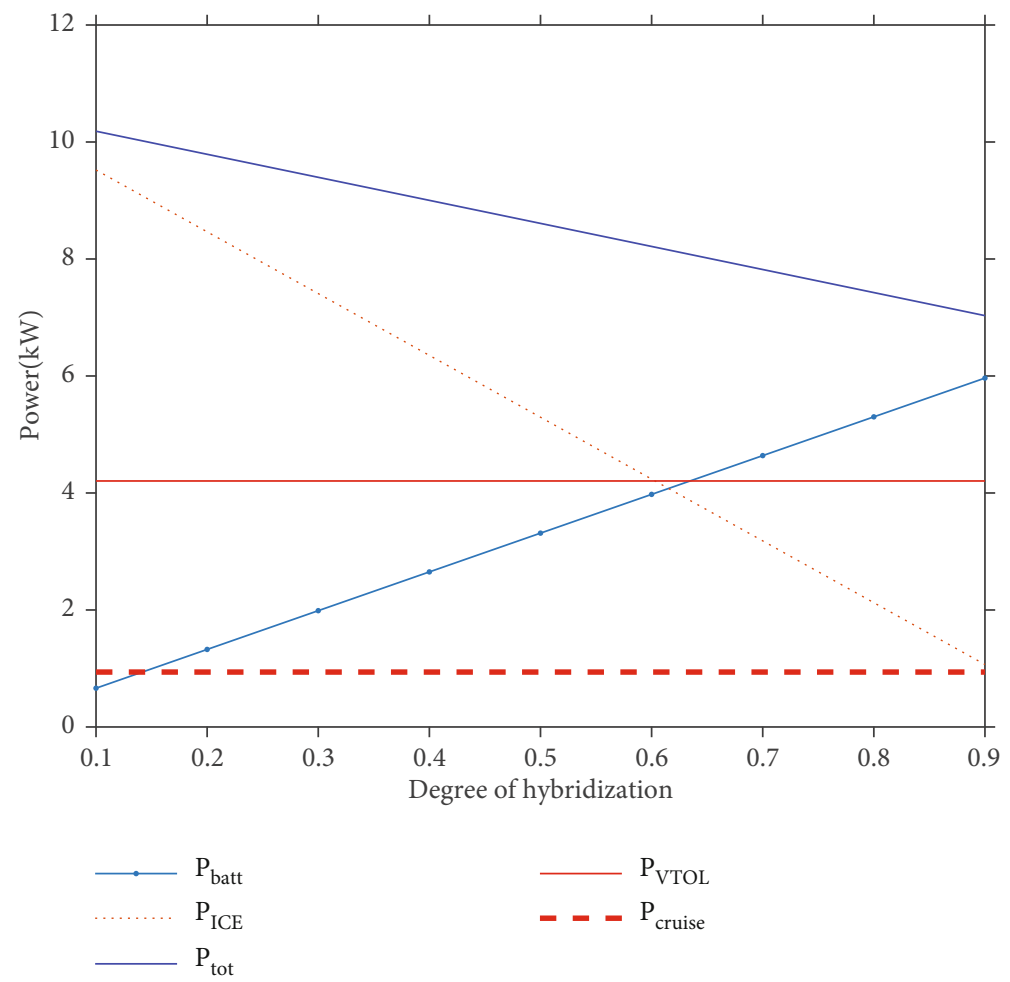

FiguRE 8: Acceptable region of $\gamma$.

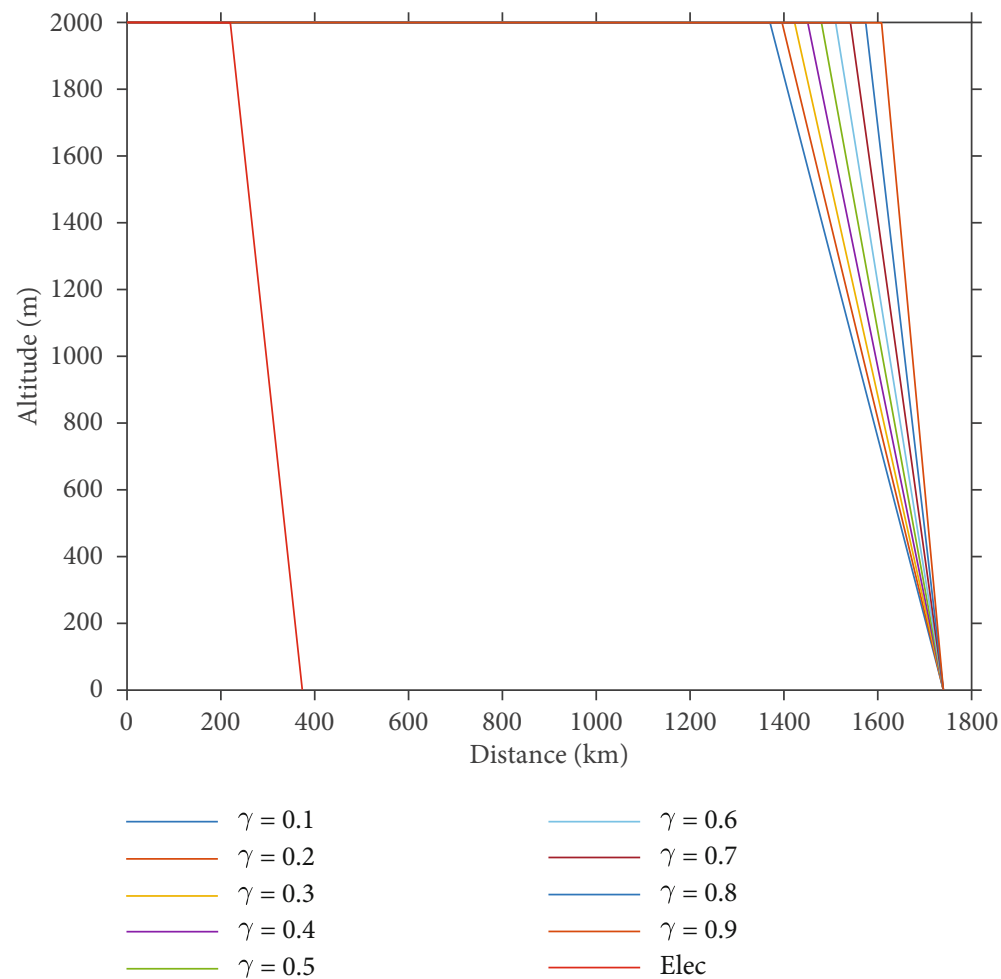

FIgURE 9: Different areas of the mission profile.

Considering the weight remains unchanged and the payload is increased to $10 \mathrm{~kg}$, the new acceptable region is shown in Figure 10.
After the payload increases to $10 \mathrm{~kg}$, the acceptable region is reduced to $\gamma \in[0.1,0.33]$. Figure 11 shows the mission profile with a payload of $10 \mathrm{~kg}$. 


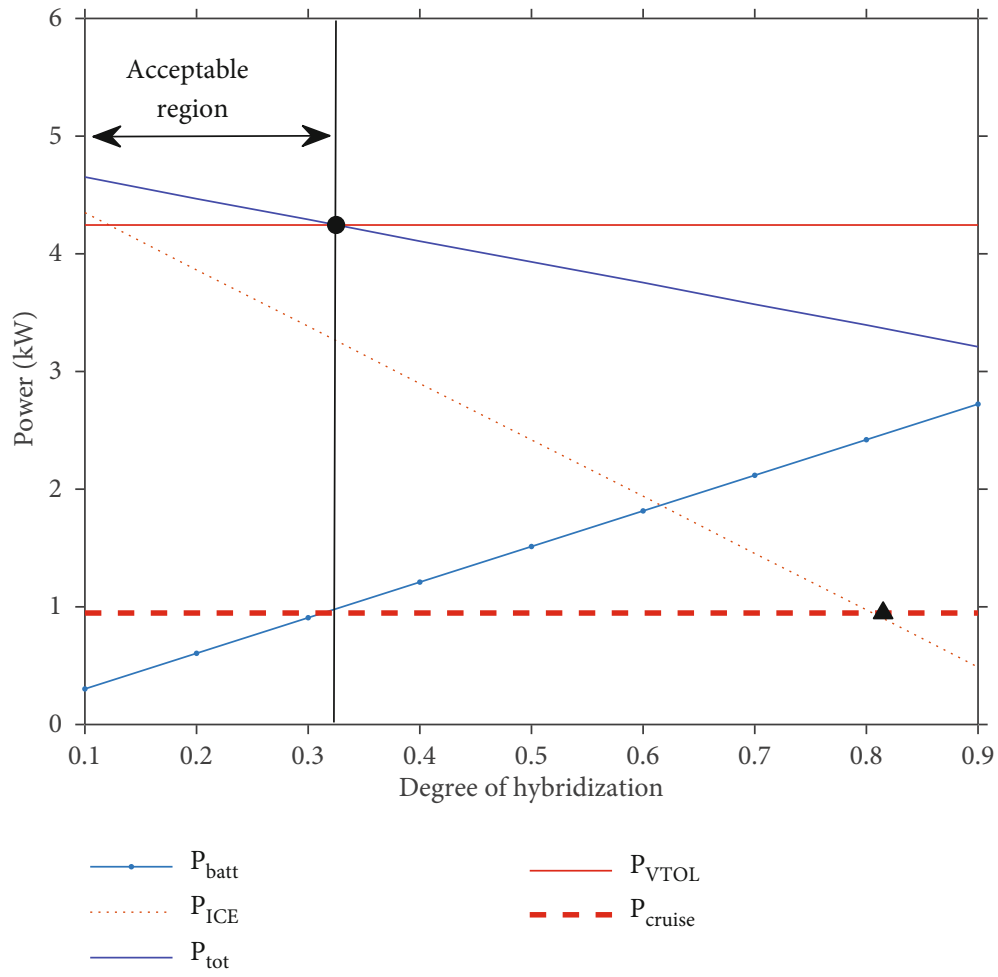

Figure 10: Acceptable region of $\gamma($ payload $=10)$.

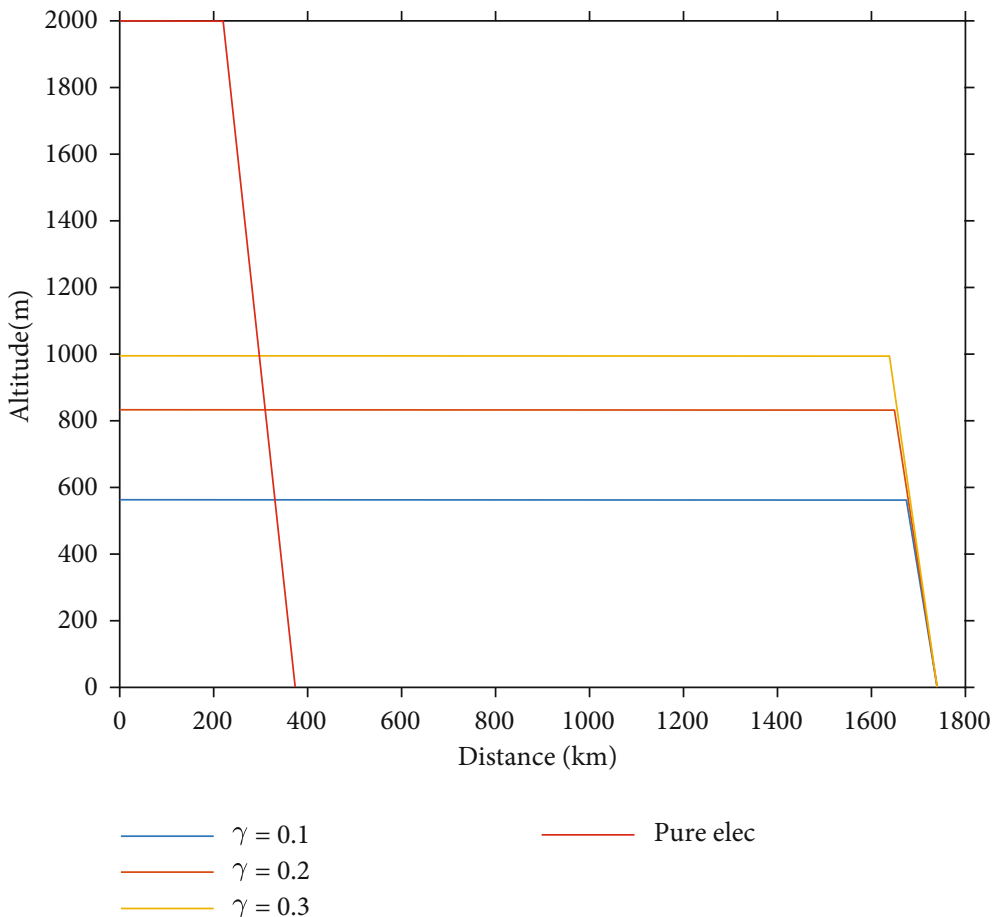

FIGURE 11: Different areas of mission profile $($ payload $=10)$.

Similarly, the larger the $\gamma$, the larger the mission profile. However, since the reduction of weight, the maximum cruise altitude is obviously affected, which is less than $1000 \mathrm{~m}$, but it can greatly improve the endurance of the pure-electric aircraft.
4.3. Payload-Range Sensitivity. Without changing the MTOM, the fuel tank of the aircraft cannot be filled with fuel to reduce the weight for more payloads. Research on the sensitivity of payload range can help to evaluate how the payload affects the range of the aircraft [25]. In this section, 


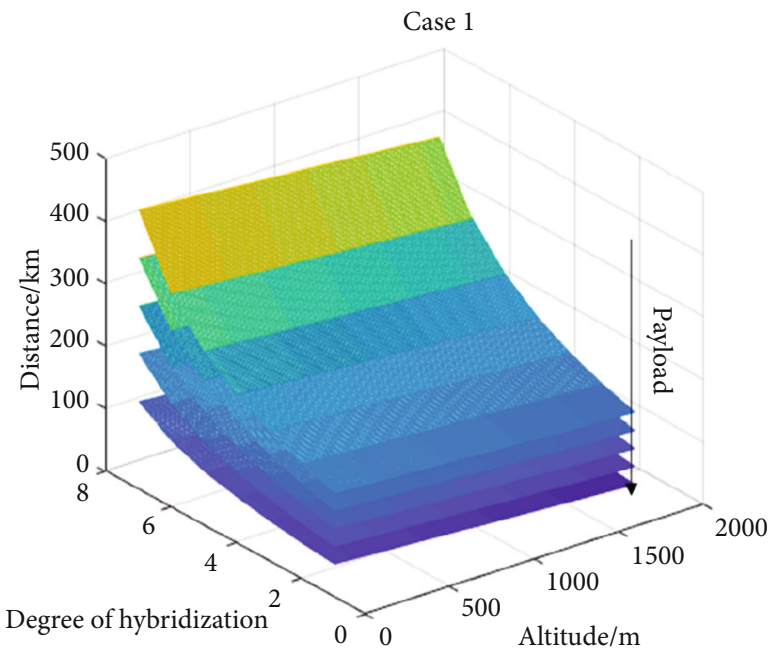

(a)

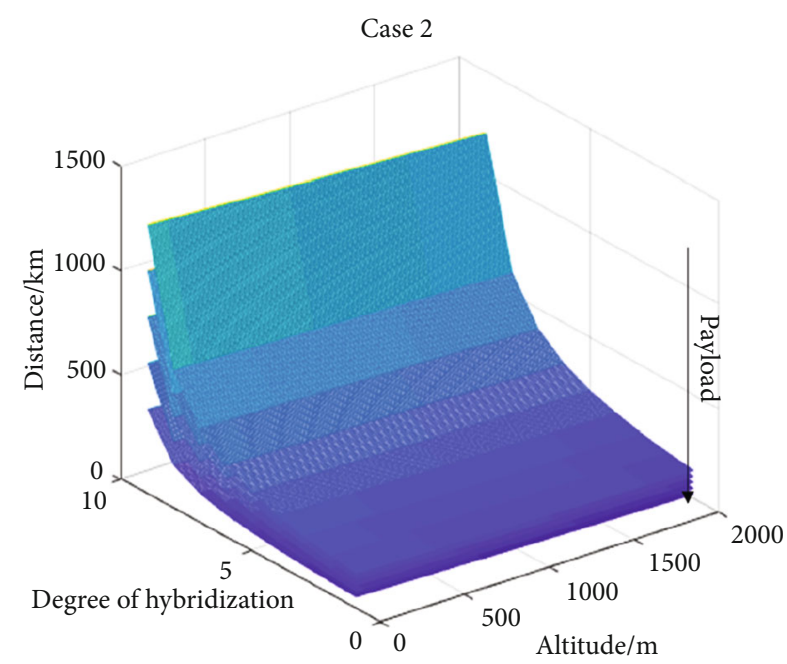

(b)

FIgURE 12: Payload-range sensitivity diagram.

we take $5 \mathrm{~kg}$ load and $8 \mathrm{~L}$ fuel as the benchmark, respectively, study the payload-range sensitivity for case 1 and case 2 , and obtain the variation of maximum range of different payloads with different $\gamma$ and altitudes, as shown in Figure 12.

It can be seen from Figure 12, the higher the $\gamma$, the greater the payload-range sensitivity at the same takeoff altitude. At the same $\gamma$ but different takeoff altitude, the payload-range sensitivity is very small. It is worth noting that in case 2, when the payload increases, the maximum takeoff altitude decreases significantly with low degree of hybridization.

\section{Conclusion}

This paper demonstrates the design method of the hybridelectric propulsion system. Different from the previous design method, this paper introduces the analysis method of the mission profile to determine the design of the hybrid-electric propulsion system and studies the payloadrange sensitivity. In addition, the design process also shows the influence of different degrees of hybridization on the takeoff altitude and cruise distance. For the hybrid-electric propulsion system, at the same weight, high degree is beneficial to the work efficiency of ICE in the entire flight process, and low degree is beneficial to higher takeoff altitude. When the MTOM of the aircraft is unchanged, the weight of the payload has a greater impact on the cruise distance when the degree is high and may affect the maximum takeoff altitude when the degree is low. Another contribution of this paper is that the analysis method and results of the mission profile can provide strong support for the research of UAM.

\section{Data Availability}

All data generated or analyzed during this study are included in this article.

\section{Conflicts of Interest}

The authors declare that they have no conflicts of interest.

\section{References}

[1] D. P. Thipphavong, R. Apaza, B. Barmore et al., "Urban air mobility airspace integration concepts and considerations," in 2018 Aviation Technology, Integration, and Operations Conference, Atlanta, Georgia, 2018.

[2] R. Frej Vitalle, Y. Zhang, B. Normann, and N. Shen, "A model for the integration of UAM operations in and near terminal areas," in Aiaa Aviation 2020 Forum, Virtual Event, 2020.

[3] K. H. Goodrich and C. R. Theodore, "Description of the NASA urban air Mobility Maturity Level (UML) Scale," in AIAA Scitech 2021 Forum, Virtual Event, 2021.

[4] W. Choi and S. Hampton, "Scenario-based strategic planning for future civil vertical take-off and landing (VTOL) transport," Journal of Aviation/Aerospace Education \& Research, vol. 29, no. 1, pp. 1-31, 2020.

[5] J. Gundlach, Designing unmanned aircraft systems: a comprehensive approach, American Institute of Aeronautics and Astronautics, Reston, VA, 2011.

[6] National Academies of Sciences, Engineering, and Medicine, Commercial Aircraft Propulsion and Energy Systems Research: Reducing Global Carbon Emissions, National Academies Press, 2016.

[7] R. H. Lenssen, Series Hybrid Electric Aircraft: Comparing the Well-to-Propeller Efficiency With a Conventional Propeller Aircraft, TU Delft, 2016.

[8] J. C. Gladin, D. Trawick, C. Perullo, J. C. Tai, and D. N. Mavris, "Modeling and design of a partially electric distributed aircraft propulsion system with GT-HEAT," in 55th AIAA Aerospace Sciences Meeting, Grapevine, Texas, 2017.

[9] F. G. Harmon, A. A. Frank, and J.-J. Chattot, "Conceptual design and simulation of a small hybrid-electric unmanned aerial vehicle," Journal of Aircraft, vol. 43, no. 5, pp. 14901498, 2006. 
[10] R. de Vries, M. Hoogreef, and R. Vos, "Preliminary sizing of a hybrid-electric passenger aircraft featuring over-the-wing distributed-propulsion," in the AIAA Scitech 2019 Forum, San Diego, California, 2019.

[11] H. Kim, G. Brown, and J. Felder, "Distributed turboelectric propulsion for hybrid wing body aircraft," in 9th International Powered Lift Conference, London, United Kingdom, 2008.

[12] R. de Vries, M. Brown, and R. Vos, "Preliminary sizing method for hybrid-electric distributed-propulsion aircraft," Journal of Aircraft, vol. 56, no. 6, pp. 2172-2188, 2019.

[13] J. T. Economou, A. Tsourdos, and S. Wang, "Design of a distributed hybrid electric propulsion system for a light aircraft based on genetic algorithm," in AIAA Propulsion and Energy 2019 Forum, Indianapolis, IN, 2019.

[14] W. J. Fredericks, M. D. Moore, and R. C. Busan, "Benefits of hybrid-electric propulsion to achieve $4 \mathrm{x}$ cruise efficiency for a VTOL UAV," in 2013 International Powered Lift Conference, Los Angeles, CA, 2013.

[15] D. F. Finger, C. Bil, and C. Braun, "Initial sizing methodology for hybrid-electric general aviation aircraft," Journal of Aircraft, vol. 57, no. 2, pp. 245-255, 2020.

[16] A. Kamal and A. Ramirez-Serrano, "Conceptual design of a highly-maneuverable transitional VTOL UAV with new maneuver and control capabilities," in AIAA Scitech 2020 Forum, Orlando, FL, 2020.

[17] U. Cakin, Z. Kaçan, Z. A. Aydogan, and I. Kuvvetli, "Initial sizing of hybrid electric VTOL aircraft for intercity Urban Air Mobility," in Aiaa Aviation 2020 Forum, Virtual Event, 2020.

[18] R. de Vries, M. T. Brown, and R. Vos, "A preliminary sizing method for hybrid-electric aircraft including aero-propulsive interaction effects," in 2018 Aviation technology, Integration, and Operations Conference, Atlanta, Georgia, 2018.

[19] L. Boggero, M. Fioriti, and S. Corpino, "Development of a new conceptual design methodology for parallel hybrid aircraft," Proceedings of the Institution of Mechanical Engineers, Part G: Journal of Aerospace Engineering, vol. 233, no. 3, pp. 1047-1058, 2017.

[20] R. Ravishankar and S. R. Chakravarthy, "Range equation for a series hybrid electric aircraft," in 2018 Aviation technology, Integration, and Operations Conference, Atlanta, Georgia, 2018.

[21] M. Wang and M. Mesbahi, "Power allocation for hybrid electric aircraft via optimal control during climb, cruise, and descent," in AIAA Scitech 2021 Forum, Virtual Event, 2021.

[22] M. Hassanalian, R. Salazar, and A. Abdelkefi, "Conceptual design and optimization of a tilt-rotor micro air vehicle," Chinese Journal of Aeronautics, vol. 32, no. 2, pp. 369-381, 2019.

[23] G. J. Leishman, Principles of Helicopter Aerodynamics, Cambridge University Press, New York, 2006.

[24] D. F. Finger, C. Braun, and C. Bil, "Comparative assessment of parallel-hybrid-electric propulsion systems for four different aircraft," Journal of Aircraft, vol. 57, no. 5, pp. 843-853, 2020.

[25] W. Lammen and J. Vankan, "Energy optimization of single aisle aircraft with hybrid electric propulsion," in AIAA Scitech 2020 Forum, Orlando, FL, 2020.

[26] http://www.gemtorch.com/product-show.php?id=64. 